\title{
직장인의 $\mathrm{SNS}$ 사용 분석을 통한 $\mathrm{SNS}$ 기획 김은주 ${ }^{*}$ 홍순근 ${ }^{* *}$ 황찬규
}

SNS planning through analysis of office workers SNS use

\author{
Eun-Ju Kim ${ }^{*} \cdot$ Soon-Geun Hong ${ }^{* *} \cdot$ Chan-Gyu Hwang ${ }^{* * *}$ \\ 요 약
}

$\mathrm{PC}$ 기반의 인터넷에서 모바일로 플랫폼의 변화가 일어난 후 SNS가 대면 교류를 대체하는 새로운 대화 매 체로 자리를 잡았다. 사용자들은 이미 SNS를 생필품으로 인식하기 시작했으며 나아가 SNS시장은 세분화 되 고 있다. 즉, 특정 대상과 컨텐츠에 집중한 수직적(Vertical) SNS의 시대로 접어들었다고 볼 수 있다. 따라서 $\mathrm{SNS}$ 기획에서 명확한 사용자 분석이 필요하며 이러한 시점에서 가장 구매력이 있는 직장인들이 SNS사용 이 유를 살펴보는 것은 SNS사업자 입장에서는 의미가 있다. 이에 본 연구에서는 'SNS사용과 자기표현 및 사회 적 지지와 직장인의 스트레스와의 관계'를 살펴봄으로써 직장인의 SNS사용 이유를 분석하였다. 그 결과 SNS 사용은 자기표현 및 사회적 지지와 관련 있었다. SNS에서의 자기표현은 직장인의 특성상 스트레스와 관련이 없었으나 $\mathrm{SNS}$ 에서의 사회적 지지는 스트레스에 영향을 미치는 것을 확인하였다.

\section{ABSTRACT}

After platform changed from PC-based internet to mobile, SNS became new interactive media which relaces face-to-face interaction. the SNS users have already begun to recognize SNS as daily necessity. SNS market has been subdivided. In other words, SNS has entered into a period of vertical SNS that focus on contents and specific target. Therefore, It is necessary to analyze users for SNS planners. For this reason, analyzing why office workers who have the most powerful purchasing power use SNS is meaningful for SNS planners. Therefore, in this study, we analyzed the reasons for using SNS of office workers by studying relationship among office workers' stress, social support, self-expression and the use of SNS. As a result, the use of SNS has a significantly positive correlation with social support and self-expression. The self-expression in the SNS is not associated with stress, but rather it is the characteristics of the office workers. However the social support in the SNS affects to stress.

$$
\text { 키워드 }
$$

Social Network Service(SNS), Self-Expression, Perceived Social Support, Stress 소셜 네트워크 서비스, 자기표현, 사회적 지지, 스트레스

\section{I. 서 론}

우리사회는 스마트 미디어 환경에 둘러 싸여 있으 며, 새로운 기술과 모델이 하루가 다르게 만들어 지고 있다[1].
모바일 디바이스의 보급이 보편화 되면서 사회 곳 곳에서 많은 변화가 일어나고 있으며, 그 중심에 SNS(Social Network Service, 이하 SNS)가 있다. 2013년 현재 사용자들은 SNS를 생필품으로 인식하기 시작했으며 $\mathrm{SNS}$ 시장은 이미 초기 진입기를 거쳐 성

\footnotetext{
* 서울벤처대학원대학교 경영학과(golkiss@ hanmail.net) ** 서울벤처대학원대학교 융합산업학과 교수(dcmlab@svu.ac.kr)

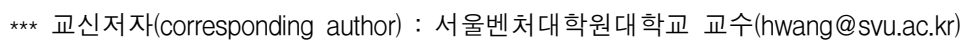


장기에 이르렀다고 보아도 과언이 아니다. 시장이 포 화됨에 따라 공급자 즉 $\mathrm{SNS}$ 사업자 입장에서 기존의 사용자수를 늘리는 트래픽 위주의 사업 모델로는 경 쟁에서 생존할 수 없는 상태에 이르렀다. 이에 SNS 시장은 새로운 사업 모델을 찾아서 날마다 세분화 되 어, 특정 대상과 컨텐츠에 집중하는 수직적(Vertical) $\mathrm{SNS}$ 의 시대로 접어들고 있다. 이에 따라서 네트워크 의 중요성보다 콘텐츠의 중요성이 더욱 부각되고 있 으며 수준 높은 콘텐츠를 제공하는 사업자가 시장을 장악하게 될 것이다[1].

새로운 기술이 제공하는 편의성과 효용성은 경험과 정보를 통해서 습득한다[1]. 사용자 입장에서 살펴보 면, SNS의 과도한 사용과 기존의 개방형 SNS에서의 사용자 경험은 이미 SNS피로도라는 말까지 생산하기 에 이르렀다. 사용자 경험이 쌓여가는 사이 시장은 공 급자 중심에서 소비자 중심으로 이동하였다. 시장의 확대에 따라 공급자가 기하급수적으로 늘어났고 소비 자는 자신의 취향에 맞는 $\mathrm{SNS}$ 를 선택하는 단계에 이 르렀다. 결과적으로 공급자입장에서 수익모델을 창출 하기 위해서는 명확한 타겟층의 설정과 타겟층의 사 용자 패턴에 대한 정확한 분석을 기반으로 한 기획이 전제되어야 수익모델을 창출할 수 있다. 사이버공간에 진출하고자 하는 기업가들은 사이버 공간에 대한 실 제적이고 현실감 있는 이해를 필요로 한다.[2]

이러한 시점에서 수익을 창출할만한 특정 집단으로 첫째, SNS에 학습되어 있으며 둘째, 일정 규모 이상 의 시장성이 있으며 셋째, 서비스 비용을 지불한 경제 적 능력이 있으며 넷째, 사용자집단구성원 간에 유사 한 문화와 경험을 보유하고 있는 층에 대한 확보가 필요하다. 이러한 여러 가지 조건에 가장 부합하는 대 상은 직장인이다. 직장인들은 $\mathrm{SNS}$ 를 소통의 매체로 사용하고 있고, SNS는 자기표현과 사회적 지지가 이 루어지는 장이기도 하다. 이러한 관점에서 그렇다면 직장인의 $\mathrm{SNS}$ 사용과 스트레스는 어떤 관계가 있을 것인지 분석해 보고자한다.

\section{II. 이론적 배경}

\section{1 스트레스}

현재 우리나라에서 가장 많이 쓰는 외래어로 스트
레스가 뽑힐 만큼 스트레스는 현대인의 일상생활과 밀접한 관계를 가지고 있다. 스트레스의 어원은 라틴 어 stringer이며 이는 팽팽히 죄다, 긴장이라는 뜻이 다. 스트레스에 대한 연구는 위협적인 자극을 받을 때 그것에 적응하려는 행동을 하게 된다는 Selye의 생리 학 중심의 연구와 스트레스에 대한 대처전략과 스트 레스 사건에 대한 개인의 평가가 스트레스 경험에 중 요하게 작용한다는 Lazarus의 이론으로 발전하여 왔 다. 신체적 심리적 긴장상태를 통틀어 스트레스라 일 컫는데 이는 신체적, 심리적 부적응을 일으키기도 한 다. 사회심리학적 관점에서 스트레스는 개인의 평균적 인 적응능력에 부담을 주는 사회·환경적 요구나 수요 가 많은 결과를 이루기 위한 수단의 부재로 인해 발 생하는 흥분 상태로 본다[3]. 이는 스트레스는 개인내 적인 요소로 인한 것보다 직장, 사회적 관계, 가족과 의 상호작용과 같은 사회 환경적인 상황에 따라 많이 좌우된다는 것이다. 우리나라의 성인은 깨어있는 대부 분의 시간을 직장에서 보내는데 직장에서는 자신을 통제하는 일이 많고 자신의 직위와 그에 대한 보상, 상사와의 관계 등이 자신의 욕구와 일치하지 않는 경 우가 많다. 실제로 통계청에서 전국 17,424 명을 대상 으로 실시한 2012년 사회조사보고서에 의하면 직장에 서 스트레스를 느끼는 사람이 12,911 명으로 $74 \%$ 에 달 해 직장 내 스트레스가 심각한 수준임을 알 수 있다.

표 1. 직장 내 스트레스 정도

Table 1. Statistics of stress in the workplace

\begin{tabular}{|c|c|c|c|}
\hline \multicolumn{2}{|c|}{$\begin{array}{l}\text { The amount of } \\
\text { feeling stress }\end{array}$} & \multirow{2}{*}{$\begin{array}{c}\begin{array}{c}\text { frequency } \\
\text { (people) }\end{array} \\
3,049\end{array}$} & \multirow{2}{*}{$\begin{array}{c}\text { rate(\%) } \\
17.5\end{array}$} \\
\hline Feeling & Severe & & \\
\hline 12,911(74.1) & Moderate & 9,862 & 56.6 \\
\hline \multirow{2}{*}{$\begin{array}{c}\text { Not feeling } \\
4,513(25.9)\end{array}$} & Weak & 3,729 & 21.4 \\
\hline & None & 784 & 4.5 \\
\hline
\end{tabular}

* 자료: 통계청.(2012), 2012년 사회조사 보고서, 통계청.

스트레스는 직장인 개개인에게는 직무만족도 저하, 결근, 재해, 자발적 실업 등으로 이어져 사회 부적응 과 같은 사회적 문제와 건강 악화로 인한 의료비의 증가와 같은 삶의 질을 떨어뜨리며, 사업주에게는 재 해 및 사고 증가로 인한 비용의 손실 및 부담 그리고 
생산성 저하를 유발시켜 경영의 악화나 도산으로 이 어지게 되며, 지역사회나 국가적인 차원에서는 경쟁력 하락으로 인한 국가 및 지역사회의 발전저해 등의 부 정적인 결과를 초래하게 된다는 점에서 이에 대한 원 인의 구명과 적절한 예방관리가 절실한 실정이다[4].

\section{$2.2 \mathrm{SNS}$ 사용자의 심리적 특성}

개인화된 콘텐츠를 가지고 있고, 개방화된 플랫폼 의 형태로 되어 있으며 참여와 공유가 가능한 미디어 를 소셜미디어라고 한다[5]. SNS는 주관적인 경험을 서로 공유하고 이에 동참하며 누구나 접근성이 용이 하도록 개방되어 있는 대표적인 소셜미디어이다. $\mathrm{SNS}$ 의 발달로 대면하지 않고도 대인간의 인간적 상 호작용이 가능해졌고, $\mathrm{SNS}$ 는 정서적인 유대를 형성 하는 가장 접근성이 좋은 채널이 되었다.

$\mathrm{SNS}$ 사용의 중심에는 온라인상에서의 자신을 나타 내고 알리고자하는 자기표현욕구가 존재한다. 자기표 현이라는 용어는 바람직한 의사소통 행위 일체를 일 컫는 말로 확신을 가지고 기술적으로 자기의 생각이 나 감정을 폭넓게 전달하는 능력이다[6]. 자기표현은 대인관계 속에서 일어나는 행동이다. 자신의 욕구, 권 리, 감정, 느낌을 표현하지 않으면 정신적 에너지는 억압이라는 형식으로 개인 내에 잠재된다. 이는 결국 심리적인 긴장상태를 유지하여 개인을 스트레스 상황 에 놓이게 하고 이는 개인의 에너지 소모를 촉진한다.

온라인은 시공간적인 제약이 덜하고 대면관계보다 자신을 표현하는 제약이 덜해 다양한 방식으로 자신 을 표현할 수 있다[7]. 사이버 공간이란 기술적 기반 위에 형성된 가상공간 이다[2]. 따라서 사람들은 실제 생활에서 자기표현을 하는 것보다 심리적 부담감이 줄어서 보다 자유스러운 자기표현이 가능할 수 있다.

$\mathrm{PC}$ 기반의 플랫폼에서 모바일 기반의 플랫폼 변화 에서 $\mathrm{SNS}$ 이용의 대중화는 특히 $\mathrm{SNS}$ 가 접속횟수와 접속시간이 늘어나면서 대면교류를 대체하는 새로운 대화 매체로 영역을 확산해 나가는 것을 볼 수 있다. 또한 웹은 단순히 문서들을 연결해주는 것에서 벗어 나 사람들을 연결해주는 웹으로 옮겨가고 있으며 소 셜 행동은 단순한 접합 형태를 뛰어넘어 핵심 기능으 로 자리 잡았다[8]. 이는 인간은 기본적으로 사회적 동물이기 때문에 대인관계를 통해 욕구를 충족시키기 때문이다. 대인관계에서의 옥구는 대인관계 내에서 인
정받고 사랑받고 있다고 느끼는 사회적인 지지로 이 어지며 이는 개인의 안녕에 영향을 미친다. 사회적 지 지는 개인에게 자신이 가치 있다는 느낌을 느끼게 하 며 소속감을 느끼게 하고 보살핌을 받고 있다고 느끼 게 한다[9]. 즉, 사회적 지지는 개인의 정신건강을 증 진시킨다.

이러한 논의를 바탕으로 개인이 직접 대면하지 않 은 $\mathrm{SNS}$ 에서의 자기표현과 사회적 지지 및 스트레스 의 관계 및 영향을 분석하고자 한다.

\section{III. 연구방법}

\section{1 연구가설}

- 가설1 : SNS사용과 자기표현은 관계가 있을 것 이다.

- 가설2 : SNS사용과 사회적 지지는 관계가 있을 것이다.

- 가설3 : SNS에서의 자기표현이 많을수록 스트 레스가 낮아질 것이다.

- 가설4: $\mathrm{SNS}$ 에서의 사회적 지지가 높을수록 스 트레스가 낮아질 것이다.

\section{2 설문 조사대상 및 방법}

설문조사는 2013년 5월부터 6월까지 두 달 동안 $\mathrm{SNS}$ 를 사용하는 직장인을 대상으로 자기보고식 설문 을 실시하였다. SNS사용은 SNS의 사용 양상과 지각 된 유용성을 중심으로 설문을 구성하였다. 자기표현은 Jourard(1964)가 개발한 자기 개방 질문지를 번안하여 수정 보완 후 사용한 임평규(2001)의 자기노출 질문 지를, 사회적 지지는 박지원(1985)이 제작한 사회적 지지 척도를 기초로 임진형(2000)이 부분 수정한 척 도를, 스트레스는 탁진국, 이강숙, 홍현숙(2002)이 개 발한 척도 중 서동미(2009)가 사용한 문항을 본 연구 에 맞게 수정 보완 하여 설문을 구성하였다[10,11,12].

설문지는 총 316 부가 회수되었으며, 이 중 설문을 완성하지 않거나 SNS를 사용하지 않는다고 응답한 16 부를 제외하였다. 설문에 응답한 직장인들의 인적 사항을 표 2 에 제시하였다.

조사 대상자들의 일반적 특징을 살펴보면, 성별분 포는 여자 51\%, 남자 49\%이며 연령별로는 30대가 
$45.7 \%$ 로 가장 많이 분포되어 있으며, 직종은 사무관 리가 $49 \%$ 로 가장 많이 분포되었다. 응답자들의 회사 규모는 대기업이 $40 \%$ 로 가장 많았으며 직장에서 총 근무한 연수는 1년 5년 미만이 35\%로 가장 많았다.

표 2. 응답자들의 인구통계학적 특성 Table 2. Demographic characteristics

\begin{tabular}{|c|c|c|c|}
\hline & Classification & $\begin{array}{c}\text { Number of } \\
\text { cases }\end{array}$ & $\begin{array}{l}\text { rate } \\
(\%)\end{array}$ \\
\hline \multirow{3}{*}{ Gen-der } & Female & 153 & 51.0 \\
\hline & Male & 147 & 49.0 \\
\hline & Sum & 300 & \\
\hline \multirow{6}{*}{ Age } & $20 \mathrm{~s}$ & 108 & 36.0 \\
\hline & $30 s$ & 137 & 45.7 \\
\hline & $40 \mathrm{~s}$ & 44 & 14.7 \\
\hline & $50 s$ & 11 & 3.7 \\
\hline & 60 s and over & 0 & 0 \\
\hline & Sum & 300 & \\
\hline \multirow{8}{*}{ Type of job } & Office management & 147 & 49.0 \\
\hline & Personnel, Production & 4 & 1.3 \\
\hline & Sales, Marketing, TM & 40 & 13.3 \\
\hline & Technical post & 8 & 2.7 \\
\hline & IT, Info-communication & 38 & 12.7 \\
\hline & Design & 10 & 3.3 \\
\hline & Specialized job & 53 & 17.7 \\
\hline & Sum & 300 & \\
\hline \multirow{6}{*}{$\begin{array}{l}\text { Size of } \\
\text { com-pany }\end{array}$} & Small & 61 & 20.3 \\
\hline & Small and medium & 47 & 15.7 \\
\hline & Mid-sized & 35 & 11.7 \\
\hline & Big & 121 & 40.3 \\
\hline & Public official & 36 & 12.0 \\
\hline & Sum & 300 & \\
\hline \multirow{6}{*}{$\begin{array}{c}\text { Total } \\
\text { leng-th of } \\
\text { serv-ice }\end{array}$} & under 1 year & 49 & 16.3 \\
\hline & 1 year $\sim 5$ years & 105 & 35.0 \\
\hline & 5 years 10 years & 64 & 21.3 \\
\hline & 10 years $\sim 15$ years & 47 & 15.7 \\
\hline & over 15years & 35 & 11.7 \\
\hline & Sum & 300 & \\
\hline
\end{tabular}

\section{IV. 분석결과}

수집된 자료는 SPSS 18.0을 사용하여 분석하였다. 우선, $\mathrm{SNS}$ 에서의 자기표현 및 사회적 지지 그리고
스트레스의 신뢰도와 평균을 알아보았다.

표 3. 변인의 신뢰도 및 평균 Table 3. Reliability and mean of variables

\begin{tabular}{|c|c|c|c|c|}
\hline Variables & $\begin{array}{c}\text { Relia-bi } \\
\text { lity }\end{array}$ & $\begin{array}{c}\text { Ave-ra } \\
\text { ge }\end{array}$ & $\begin{array}{l}\text { Standard } \\
\text { deviation }\end{array}$ & Criterion \\
\hline SNS use & .70 & 3.21 & .94 & \multirow{4}{*}{$\begin{array}{c}\text { Five } \\
\text { point scale }\end{array}$} \\
\hline $\begin{array}{c}\text { Self-Expression } \\
\text { in SNS }\end{array}$ & .88 & 2.61 & .72 & \\
\hline $\begin{array}{c}\text { Perceived } \\
\text { Social Support } \\
\text { in SNS }\end{array}$ & .84 & 3.28 & .74 & \\
\hline Stress & .91 & 2.44 & .59 & \\
\hline
\end{tabular}

측정항목들의 Cronbach's $\alpha$ 계수가 .70이 이상으로 연구를 구성하는 변인 모두 내적 일관성이 높다.

연구가설 1 과 2 를 검증하기 위해 $\mathrm{SNS}$ 사용과 자기 표현 및 사회적 지지의 관계를 알아본 결과 세 변수 모두 유의한 양의 상관관계가 나타났다. SNS사용과 자기표현 그리고 사회적 지지는 관련성을 가지고 있 는 것으로 나타났다.

표 4. 변인 간 상관관계 분석 Table 4. Variables correlation analysis

\begin{tabular}{|c|c|c|c|}
\hline Variables & $\begin{array}{l}\text { SNS } \\
\text { use }\end{array}$ & $\begin{array}{l}\text { Self-Expression } \\
\text { in SNS }\end{array}$ & $\begin{array}{c}\text { Perceived } \\
\text { Social } \\
\text { Support } \\
\text { in SNS }\end{array}$ \\
\hline SNS use & 1 & & \\
\hline $\begin{array}{c}\text { Self-Expression } \\
\text { in SNS }\end{array}$ & $.49^{\star \star}$ & 1 & \\
\hline $\begin{array}{l}\text { Perceived Social } \\
\text { Support in SNS }\end{array}$ & $.35^{\star \star}$ & $.40^{\star \star}$ & 1 \\
\hline
\end{tabular}

가설3을 검증하기 위하여 $\mathrm{SNS}$ 에서의 자기표현이 스트레스에 미치는 영향을 알아보았다. SNS에서의 자기표현을 독립변인으로, 스트레스를 종속변인으로 한 회귀분석 모형의 $\mathrm{F}$ 통계값은 1.31 로 통계적으로 유의하지 않았다. 연구 결과 자기표현은 스트레스에 영향을 미치지 않는 것으로 드러났다. 
표 5. 변인 간 회귀분석

Table 5. Variables regression analysis

\begin{tabular}{|c|c|c|c|c|c|c|}
\hline \multirow{2}{*}{$\begin{array}{c}\text { Independ-ent } \\
\text { variables }\end{array}$} & \multicolumn{2}{|c|}{$\begin{array}{c}\text { Non-standar-dize } \\
\text { d coefficient }\end{array}$} & \multirow{2}{*}{$\begin{array}{c}\begin{array}{c}\text { Standard } \\
\text { coefficient }\end{array} \\
\beta\end{array}$} & \multirow{2}{*}{$t$} & \multirow{2}{*}{$\begin{array}{l}\mathrm{R}^{2} \\
\text { (adj.R }\end{array}$} & \multirow{2}{*}{$\mathrm{F}$} \\
\hline & B & $\begin{array}{l}\text { Standa-rd } \\
\text { error }\end{array}$ & & & & \\
\hline (Constant) & 45.94 & 2.56 & & $17.98^{\text {**** }}$ & \multirow{2}{*}{$\begin{array}{c:c}.004 \\
(.001)\end{array}$} & \multirow[b]{2}{*}{1.31} \\
\hline $\begin{array}{c}\text { Self- } \\
\text { expression }\end{array}$ & .25 & .10 & .15 & 1.14 & & \\
\hline
\end{tabular}

마지막으로 가설 4 를 검증하기 위하여 SNS에서의 사회적 지지를 독립변인, 스트레스를 종속변인으로 회 귀분석을 한 결과 $\mathrm{F}$ 통계값은 7.18 이며 유의확률은 .01으로 유의수준 .01에서 회귀모형이 통계적으로 유 의하다고 할 수 있다.

표 6. 변인 간 회귀분석

Table 6. Variables regression analysis

\begin{tabular}{|c|c|c|c|c|c|c|}
\hline \multirow{2}{*}{$\begin{array}{c}\text { Independ-ent } \\
\text { variables }\end{array}$} & \multicolumn{2}{|c|}{$\begin{array}{c}\text { Non-standa-rdiz } \\
\text { ed coefficient }\end{array}$} & \multirow{2}{*}{$\begin{array}{c}\begin{array}{c}\text { Standard } \\
\text { coefficient }\end{array} \\
\beta\end{array}$} & \multirow{2}{*}{$\mathrm{t}$} & \multirow{2}{*}{$\begin{array}{c}\mathrm{R}^{2} \\
\left(\mathrm{adj} . \mathrm{R}^{2}\right)\end{array}$} & \multirow{2}{*}{$\mathrm{F}$} \\
\hline & B & $\begin{array}{c}\text { Stand-ar } \\
\text { d error }\end{array}$ & & & & \\
\hline (Constant) & 37.44 & 1.80 & & $20.85^{\text {**** }}$ & \multirow[b]{2}{*}{$\begin{array}{c:c}.024 & \\
(.020) & \end{array}$} & \multirow[b]{2}{*}{$7.18^{\text {** }}$} \\
\hline $\begin{array}{c}\text { Perceived } \\
\text { Social } \\
\text { Support }\end{array}$ & -.10 & .04 & -1.5 & $-2.68^{* *}$ & & \\
\hline
\end{tabular}

즉, $\mathrm{SNS}$ 에서의 사회적 지지가 높을수록 스트레스 는 감소하는 것을 알 수 있다. 반면 $\mathrm{SNS}$ 에서의 자기 표현은 스트레스에 유의미한 영향을 미치지 않는 것 으로 나타났다.

\section{V. 결 론}

본 연구의 결과와 그에 따른 논의는 다음과 같다. 첫째, SNS사용이 높을수록 자기표현도 높다. 인터넷 공간에서 직장인이 자신을 표현한다는 것은 한편으로 위험을 무릎 쓰고 자기노출을 한다는 것을 의미한다. 이 두 변인들 사이의 인과관계는 알 수 없지만 SNS 사업자 입장에서 해석한다면 사용자가 자주 들러 자 신을 표현하는 SNS가 되려면 사용자들끼리 신뢰관계 를 높일 수 있는 구조를 만들어야 한다는 점이다.
둘째, $\mathrm{SNS}$ 사용이 높을수록 사회적 지지도 높다. 사회적 지지는 인간이 사회적 동물이기에 누구나 받 고 싶은 반응이다. 사회적 지지를 컨텐츠화해서 기획 에 구성한 대표적 사례인 페이스북에서처럼 상대의 의견에 대하여 '좋아요' 표시를 하는 것이다.

$\mathrm{SNS}$ 사용 빈도를 높이는 것은 트래픽을 높이는 길이 다. 그러기위해서는 $\mathrm{SNS}$ 기획단계에서 구조적으로 사회 적 지지 시스템을 구체화하는 다양한 설계가 필요하다.

셋째, $\mathrm{SNS}$ 사용에서 자기표현은 직장인의 스트레스 에 영향을 주지 않는 것으로 나타났다. 이러한 결과는 직장인의 특성을 반영하는 것으로 해석된다. $\mathrm{SNS}$ 환경 은 자신의 정보가 누구에게나 흘러갈 수 있음을 의미 한다. 다시 말하면 직장인 입장에서 자신의 비지니스와 관련된 이해 당사자에게도 자신의 정보가 노출될 수 있음을 의미한다. 그 이해 당사자는 직장동료이거나 상 사일 수도 있다. 이는 디지털 사회에서 개인 정보 노출 에 대한 위험을 반영하는 결과이기도하다. 디지털 사회 는 인위적이고 개인적이고 계산된 피해를 유발하는 위 험성을 가지고 있다. 실제로 인터넷 사용자들은 개인의 사생활 침해, 개인 정보 유출등과 관련된 위험이 내재 된 상태에서 서비스를 이용한다[13]. 그런 의미에서 직 장인에게 자기표현은 스트레스 해소에 도움이 되는 행 위가 아니며 오히려 조심해야할 행동이다. 따라서 직장 인을 대상으로 한 SNS의 경우, 사용자 개인정보에 대 한 보호기능이 기획단계에서 특별히 염두에 두어야할 요소임을 시사적으로 보여주는 결과이다.

넷째, SNS사용에서 사회적 지지는 직장인의스트레 스에 영향을 미친다는 결과가 나왔다. 사회적 지지에 는 정서적지지 뿐만 아니라 정보적지지, 평가적 지지 도 포함된다. 따라서 직장인들은 $\mathrm{SNS}$ 내에서 정서적 지지 뿐만 아니라, 정보적 지지와 평가적 지지를 받으 면서 스트레스와 관련된 문제의 해결책을 모색하는 것으로 보인다. 따라서 직장인 대상의 $\mathrm{SNS}$ 를 기획함 에 있어서 정서적 지지 뿐만 아니라, 정보 제공의 양 과 질에 대한 고려, 다양한 평가적 지지 방법에 대한 요소를 고려하여 구성하여야 한다.

\section{참고 문헌}

[1] Seong-Cheol Jin and Won-Jun Park, "A study on the use content film of Internet VOD service users", The Journal of the Korea 
Institute of Electronic Communication Sciences, Vol. 8, No. 2, pp. 261-255, 2011.

[2] Se-Ill Choi, "A Road-map for an e-Commerce Development", The Journal of the Korea Institute of Electronic Communication Sciences, Vol. 7, No. 4, pp. 897-904, 2012.

[3] Lazarus, R. S., Psychological stress and the coping process, McGraw-Hill, 1966.

[4] Chang SJ, Koh SB, Kang MG, Cha BS, Park JK, Hyun SJ, Park JH, Kim SA, Kang DM, Chang SS, Lee KJ, Ha EH, Ha M, Woo JM, Cho JJ, Kim HS and Park JS, "Epidemiology of Psychosocial Distress in Korean Employees", Journal of preventive medicine and public health, Vol. 38, No. 1, pp. 25-37, 2005.

[5] Woon-Chul Bae, Social media marketing, Information Publishing Group, 2012.

[6] Adler, Ronald B., Looking Out, Looking in, Wadsworth, 2011.

[7] Schau, H. J. • Gilly, M. C., "We are what we post? Self-presentation in personal web space", Journal of consumer research, Vol. 30, No. 3, pp. 385-404, 2003.

[8] Adams, P., Grouped: How small groups of friends are the key to influence on the social web, New Riders, 2011.

[9] Cobb, S., "Presidential Address-1976. Social support as a moderator of life stress", Psychosomatic medicine, Vol. 38, No. 5, pp. 300-314, 1976.

[10] Pyeong-gyu Lim, "Differences of self- disclosure in real and cyberspace contexts : examining the interaction between context and personal characteristics", The graduate school of Yonsei university, 2001.

[11] Jin-hyung Lim, "The relation among kindergarten beginning teacher's self-efficacy, social support and occupational stress", The graduate school of Ewha womans university, 2000.

[12] Dong-mi Seo, "A Study on the effect of selfefficacy, personality(HEXACO), and job stress at work", The graduate school of education of Ewha womans university, 2009.

[13] Seong-cheol Jin and In-kyung Kim, "A Study on the Psychological anxiety on Private information leakage to likelihood of internet users", The Journal of the Korea Institute of
Electronic Communication Sciences, Vol. 6, No. 5, pp. 731-738, 2011.

$$
\text { 저자 소개 }
$$

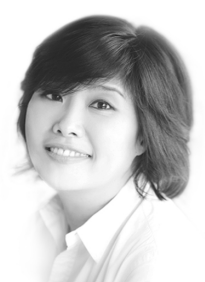

\section{김은주(Eun-Ju Kim)}

1990년 상명여자대학교 국어교육학 과 졸업(문학사)

2003년 고려대학교 교육대학원 졸 업(교육학석사)

2011년 현재 서울벤처대학원대학교 대학원 경영 학 과 박사과정

현) 창조게릴라 대표

※ 관심분야 : 디지털콘텐츠 및 멀티미디어 방송통 신, 유비쿼터스 및 IT기술

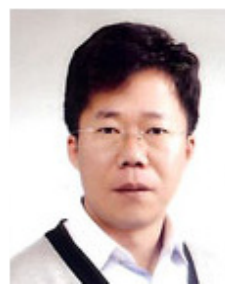

\section{홍순근(Soon-Geun Hong)}

1988년 서울대학교 경제학과 졸업 (경제학사)

1990년 한국과학기술원 산업공학과 석사 졸업(공학석사)

2008년 한국과학기술원 경영공학과 박사 졸업(공학박사) 2013년 현재 서울벤처대학원대학교 교수 ※ 관심분야 : 유비쿼터스 및 IT기술, 유비쿼터스 도시

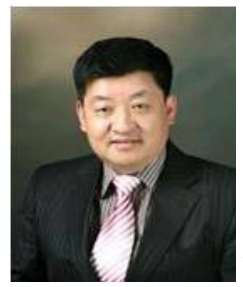

\section{황찬규(Chan-Gyu Hwang)}

1988년 서울대학교 토목공학과 졸 업(공학사)

1990년 서울대학교 공과대학원 토 목공학과 졸업(공학석사)

1999년 미 코넬대학교 대학원 토목환경공학과 졸업 (공학박사)

약력) KIST 위촉연구원, 미 선급협회 $\mathrm{ABS}$ 구조 엔지니어 2004년 현재 서울벤처대학원대학교 교수 ※ 관심분야 : 유비쿼터스 및 IT기술, 유비쿼터스 도시 